\title{
Porosity and Lithology Prediction in Eve Field, Niger Delta Using Compaction Curves and Rock Physics Models
}

\author{
M. T. Olowokere, J. S. Ojo \\ Department of Applied Geophysics, Federal University of Technology, Akure, Nigeria \\ E-mail: olowo_mt@yahoo.com \\ Received January 8, 2011; revised May 10, 2011; accepted June 12, 2011
}

\begin{abstract}
The primary objective of this study is to investigate the porosity-depth trends of shales and sands and how they affect lithologies. Compaction curves from well logs of five wells were determined using interval transit time from sonic logs. The depth of investigation lies between $1087 \mathrm{~m}$ and $2500 \mathrm{~m}$. Based on the shale and sand trend modeling, the study intends to determine the model to be used for lithology prediction at various depths given the interplay between shale and sand compaction. The improved understanding of the physical properties of shales and sands as a function of burial depth was demonstrated, in conjunction with a good understanding of how compaction affects lithology. The compaction curve for shale and sand lithologies varies with shale being parabolic in form, and sands with linear and exponential in nature. Plots of sonic porosity against depth show great dispersion in porosity values while plotting porosity values against depth for different lithologies produced well-defined porosity trends. This shows decrease in porosity with depth. The negative porosity trend is less marked in sandstones, and faster in shale which suggests that it is possible to make accurate porosity predictions using compaction trend. The porosity trend showed exponential relationship at small depth less than $2500 \mathrm{~m}$. The linear and exponential models are not dependable at large depth. The result shows that the compaction models applicable for sandstones do not necessary apply for shales.
\end{abstract}

Keywords: Compaction Trend, Lithology, Porosity, Reservoir Characteristic, Velocity Logging, Sand-Shale

\section{Introduction}

Various authors have proposed different theoretical models to show the fluid-solid interaction in reservoir rocks for the purposes of both porosity and lithology prediction and fluid substitution (e.g. Bjørlykke, 1998; and Ehrenberg, 1990). However, these models can only be applied under certain conditions because the theories have some limitations. Athy, (1930); Magara, (1976a); Sclater and Christie, (1980), Magara (1980) Liu and Roaldset (1994) and Selley (1978)) have proposed a variety of models that shows the relationship between porosity and depth. Magara (1980) and Selley (1978) used linear porositydepth relationship to describe diagenetic changes affecting compaction. A parabolic relationship has been proposed by Liu and Roaldset (1994). Exponential curves were probably first introduced by Athy (1930) to describe porosity in shale. Sclater and Christie (1980) used exponential curves for porosities in sandstone, siltstone and chalk in the Central Graben of the North Sea, but their exponential curve for shale was criticized by Bald- win and Hutler (1985) who proposed a power-law curve for shale compaction (although they agreed with Sclater and Christie's sandstone compaction curve). Schmokker and Halley (1982) proposed an exponential curve for carbonate after their work in South Florida Basin. Using exponential curves to describe normal compaction in shale were also favoured by Korvin, (1984); Magara, (1980); Selley, (1978); and Haung and Gradstein (1990). Issler, 1992 used the time-average equation of Wyllie et al. (1956) to estimate porosity and clay content in consolidated formations.

This paper is a unique study of porosity prediction in the Niger Delta using compaction curves to improve reservoir modelling and production.

In this study, we derive the local shale and sand compaction trend for the Eve (gas-and-oil) field by integrating rock physics modeling with well-log and seismic data analysis. This model is based on the calibration of core and well-log data. Based on the compaction trend modeling, we demonstrate that improved understanding of the physical properties of shales as a function of burial 
depth, in conjunction with a good understanding of how compaction affects rock properties of sandstones, will improve our ability to characterize and predict porosity and lithology of sandstone reservoirs embedded in shales. Log information from nine wells within the study area was used because they are representative of various types of reservoir quality: well developed sands, marginal producing sands, and non-producing units.

In order to predict porosity from a specific rock property, prior to drilling, the particular rock property must be known or predictable. Depth to a prospect is usually well constrained, so a compaction curve is easily applied. However, unless the compaction curve is based on local data, the prediction uncertainty will commonly be too large to be useful. An approach to porosity prediction based on the compaction process and parameter, depth that is usually predictable is used. This approach focuses on compaction and cementation, which consider total porosity loss with depth of burial. This in part accounts for the wide range of porosity, at any given depth, in the data sets. The depositional porosity in shales is normally much higher (60\% - 80\%) than in sands (about 40\%), but we expect a shallow crossover with depth due to the mechanical collapse of the shales. The platy clay fabric in the shales is more prone to compaction than the assemblage of spherically shaped grains in sands; hence, the more rapid mechanical porosity reduction in shales than sands.

Linear and nonlinear regression are employed to de- rive porosity, shale volumes, so that the effects of lithology, fluid, temperature, pressure and other factors can be compensated for. This method requires log data and core data as inputs, and the outputs are reservoir parameters. The method was tested on field data from a number of reservoirs from Eve Field, Niger Delta and obtains satisfactory results.

\section{Location of the Study Area}

Figure 2 shows the general characteristic of the reference field "Eve oil field" located southeast of Lagos, Nigeria, just offshore at the western end of the Niger Delta. Water depth is approximately $15 \mathrm{~m}$.

\section{Data and Method of Study}

The study area, which covers about $25 \mathrm{~km}^{2}$ in the central part of Eve Field, was selected for three main reasons: (1) the good quality of the surface seismic, (Figure 3) (2) a better definition of structural features, which is simpler than the rest of the area, and (3) the well control represented by 11 wells, most of them with a complete set of well logs.

\subsection{Well Data}

To date, 66 wells and 3 horizontal sidetracks have been drill in the field since discovery encountering hydro-

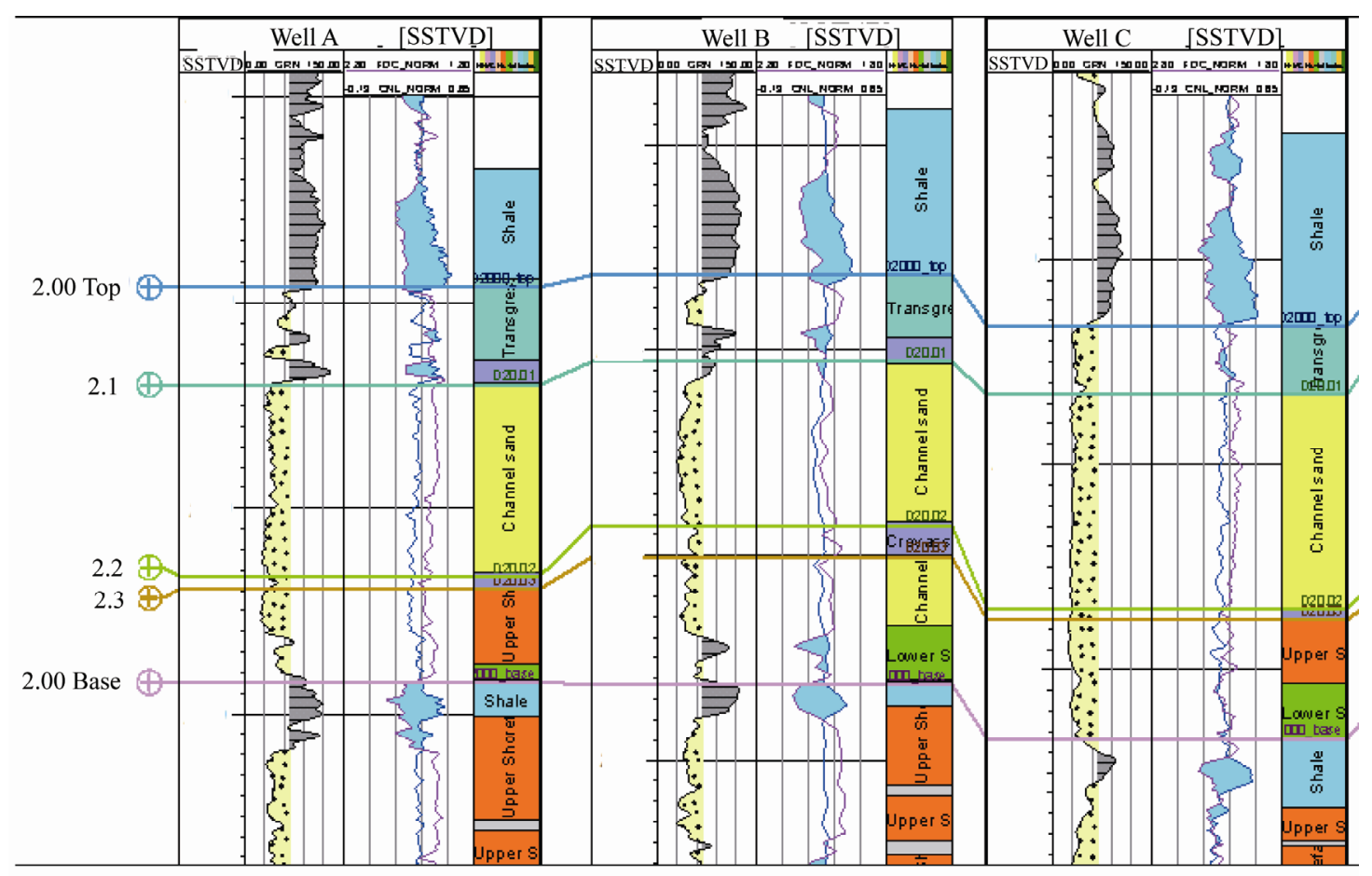

Figure 1. Gamma-ray correlation for Eve wells A, B, and C. 


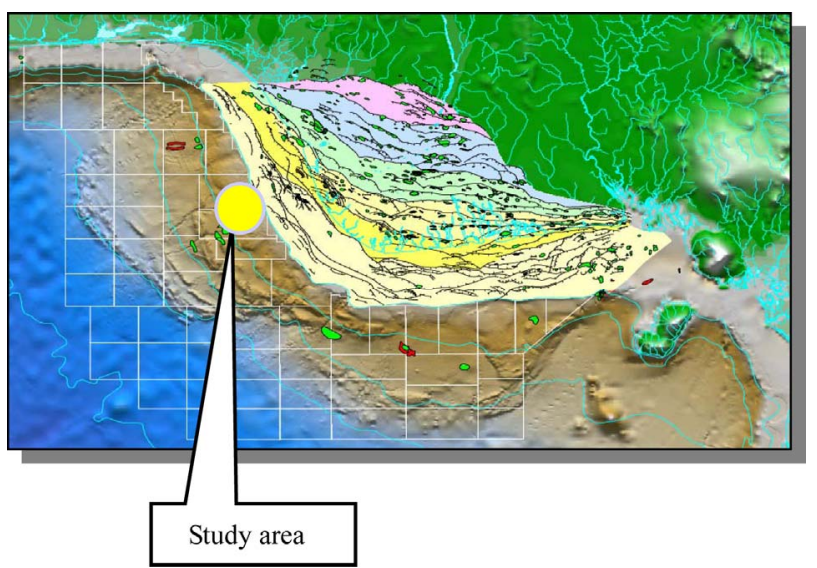

Figure 2. Location of Eve Field.

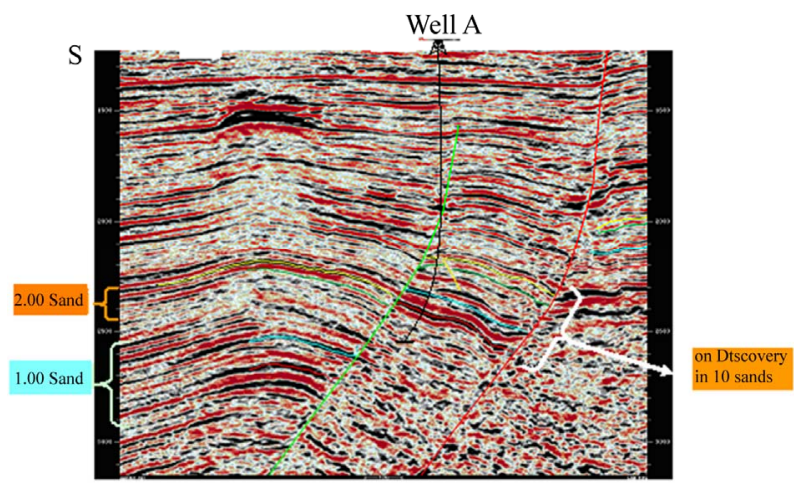

Figure 3. Seismic cross-section showing the main structural features in Eve Field.

carbon between 2135 and $3811 \mathrm{~m}$. There are thirteen wells with Check-shot data.

\subsection{Log Data}

The field is covered with full suite of basic petrophysical logs. All the wells have gamma ray and resistivity logs, with about $65 \%$ coverage of SP log. Neutron logs have about $80 \%$ well coverage, while the Density logs are available in all the wells except well 12 and the 6 sidetracks. The field has a modern vintage coverage of resistivity logs ((LLD, LLS, MSFL). However, the old vintage resistivity is available in Wells A. B and C have induction resistivity in addition to the laterolog. Compressional sonic was logged in 15 wells.

There is no Shear Sonic logged in the entire field. The log prints and digital data quality were checked and judged to be of good quality and have been used for the formation evaluation. To predict petrophysical properties such as porosity, it is important to understand the effect of depth on this variable. Compaction trend plays an important role in helping to establish the systematic relationships. The compaction trends were used to find sta- tistical relations between depth and log properties.

\subsection{Well-Log Signature, Correlation, and Petrophysical Analysis}

The recorded suite of logs can be grouped into two categories: properties that affect seismic-wave propagation in the subsurface (e.g., compressional- and shearvelocity logs $(\mathrm{m} / \mathrm{s})$, and density $\log (\mathrm{g} / \mathrm{cc}))$ and properties of interest for reservoir description but which do not directly affect seismic-wave propagation (e.g. porosity (\%), water saturation (\%), and clay content).

Petrophysical analysis through conventional cross-plots is the key to relating the two groups. Logs were carefully edited to compensate for washouts, cycle skipping, environmental corrections, and any other problems. Selected logs from Eve wells (Figure 4(a) and 4(b)) show the responses from different lithologies of Agbada Formation.

\section{Calculating Porosity}

Evaluation parameters, matrix density ( $\mathrm{pma}$ ) of $2.65 \mathrm{~g} / \mathrm{cc}$ and cementation exponent $(\mathrm{m})$ of 1.6 were obtained from core analyses while a saturation exponent (n) value of 1.8 was assumed in the absence of core measured data. The formation water resistivity $(\mathrm{Rw})$ values were obtained from clean water bearing zones using the Pickett plot method. The Porosity was calculated from density logs using equation -

$$
\phi=\frac{\rho_{m a}-\rho_{b}}{\rho_{m a}-\rho_{f l}}
$$

where $\phi=$ porosity

$\rho_{\text {ma }}=$ Matrix grain density

$\rho_{f l}=$ Density of pore fluid

$\rho_{b}=$ Formation bulk density

Calculated porosity values range between $25 \%$ and $31 \%$.

\section{Rock-Physics Trends and Crossplot Analysis}

To understand the governing compaction laws for the Agbada Formation in Eve Field, there is need to investigate the porosity-velocity relationship and to place the data points in a frame of reference. This frame will be sandstones from an active oil company's database named Proprietary's model which includes more than 70 samples of sandstones with varying porosity and clay content analyzed at an effective pressure of $40 \mathrm{Mpa}$, similar to the pressure of the reservoir in the field.

Velocity versus porosity in selected wells was crossplotted to see how the well-log data fall within the framework of the reference trends. 

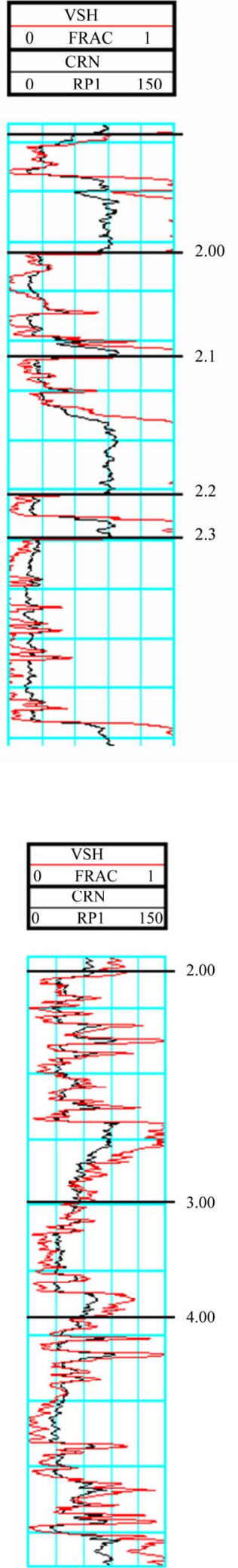

TVDSS

m

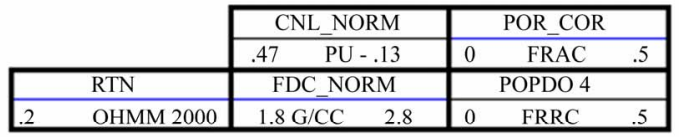

2165

2180

2195

2210

2225

2240

2255

2270

2285

2300

2315

2330

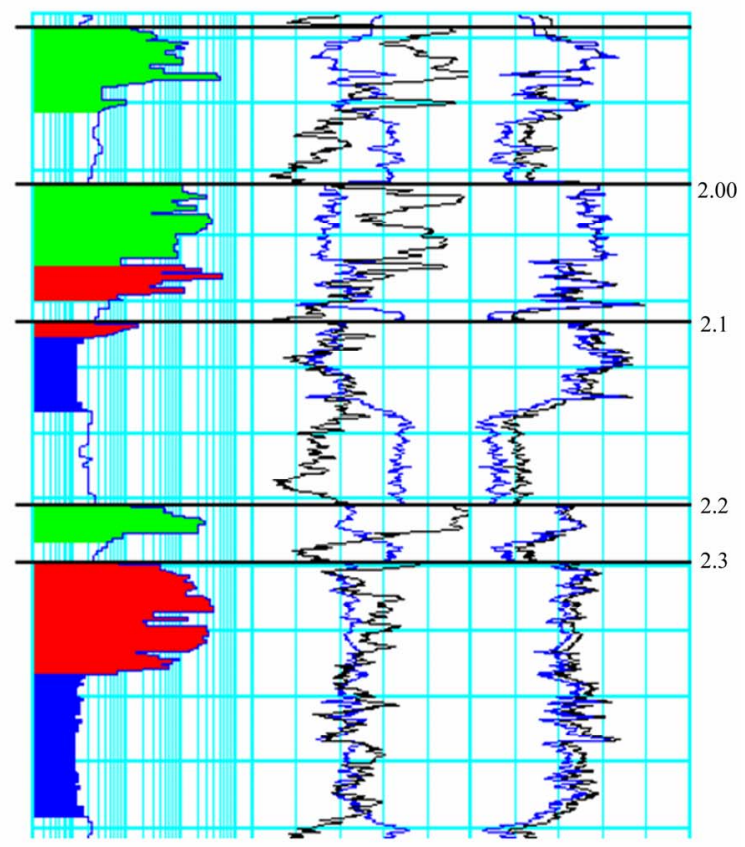

(a)
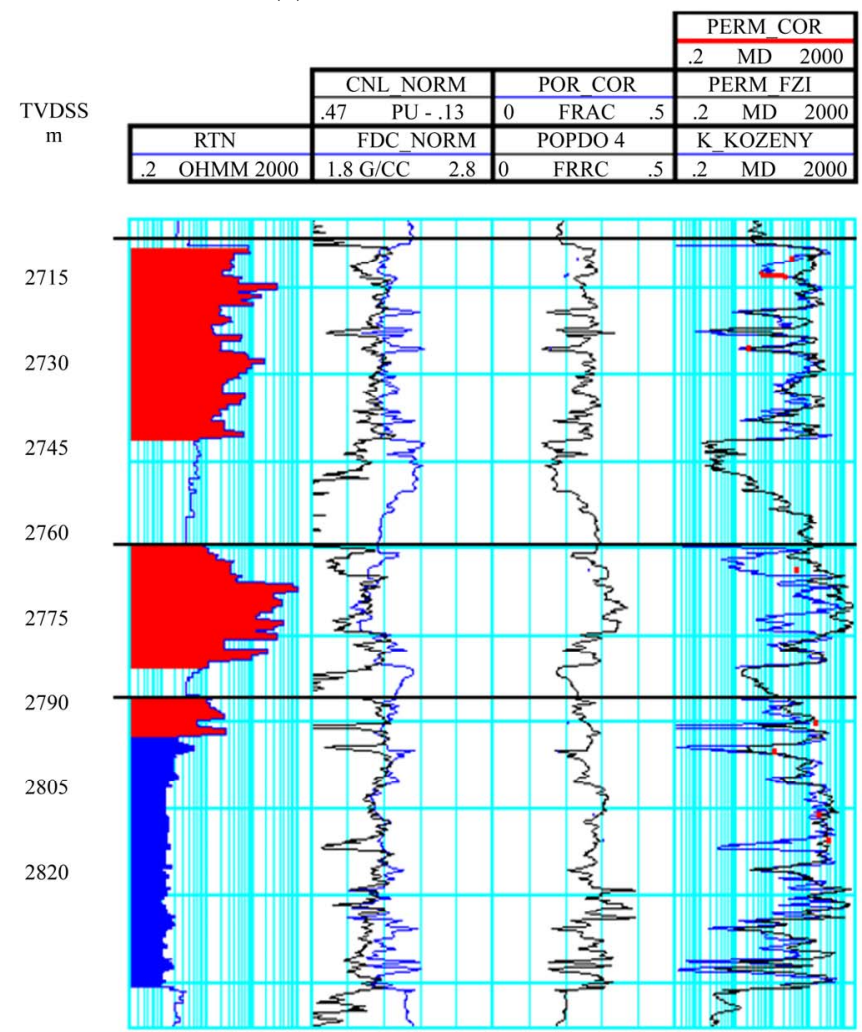

(b)

Figure 4. (a): Well logs from Eve well A showing the response from 2.00 level; (b): Well logs from Eve well B showing the response from other reservoir levels. 


\section{Discussion of Results}

In Figure 5, we crossplot velocity and density-porosity for Eve wells A, B and C individually and combined. Because the caliper indicates good borehole condition through most of the section, the data are not filtered to remove effects for washed-out intervals. From this crossplot we can see that there is a good correlation between Proprietary data and the Eve data. There is a better match between Proprietary model and the Eve data where the sands are clean. The data points for rocks with porosities between 0 and 5\% fall outside Proprietary model and these lithologies exhibit the highest scattering in the cross-plots. There are two main trends shown in the cross-plot, one for lithologies with velocities higher than about $1372 \mathrm{~m} / \mathrm{s}$ and other for lithologies with velocities lower than $1372 \mathrm{~m} / \mathrm{s}$. The first class of lithology corresponds to shaly-sands that are partly represented by Proprietary database when the clay content is between 18 and $50 \%$. The second class is associated with shales. The high scattering of these rocks can likely be related to the high clay content, which affects the compaction of the rock, the pore geometry and the aspect ratio.

The main reservoir in the field is associated with rocks with porosities that are higher than $10 \%$. These rocks fall between Proprietary zero-clay reference line and the reference line for clay contents between 12 and $17 \%$. These rocks are composed of clean sands that have velocities ranging from 1220 to $1372 \mathrm{~m} / \mathrm{s}$.

Rock physics depth trends for shales (blue) and sands (red), juxtaposed on well-log data from Well B penetrating D levels are shown in Figure 6. For a better illustration of low porosity points (i.e., for shales) the density-porosity for this example is calculated using sandstone as the density of the matrix (2.65 g/cc), which explains why the porosity looks overestimated. We can see correlation between velocity and gamma ray, and velocity and porosity.

Moreover, porosity correlates with gamma ray-the smaller gamma ray the larger porosity. Green color corresponds to low shale content while purple color indicates high shale content.

The observed velocity-porosity-shale dependence supports the fact that the Proprietary type rock physics model can explain the behavior of the velocity porosity relation in the field. In this model, velocity is affected by porosity and clay content, porosity being the main factor. For the whole section of Agbada, velocity is a good indicator of lithology. Thus, velocities higher than 1372 $\mathrm{m} / \mathrm{s}$ are most likely associated with sandstones, while velocities lower than $1372 \mathrm{~m} / \mathrm{s}$ are most likely associated with shales and siltstones.

The plot between $\mathrm{Vp} / \mathrm{Vs}$ and acoustic impedance colour

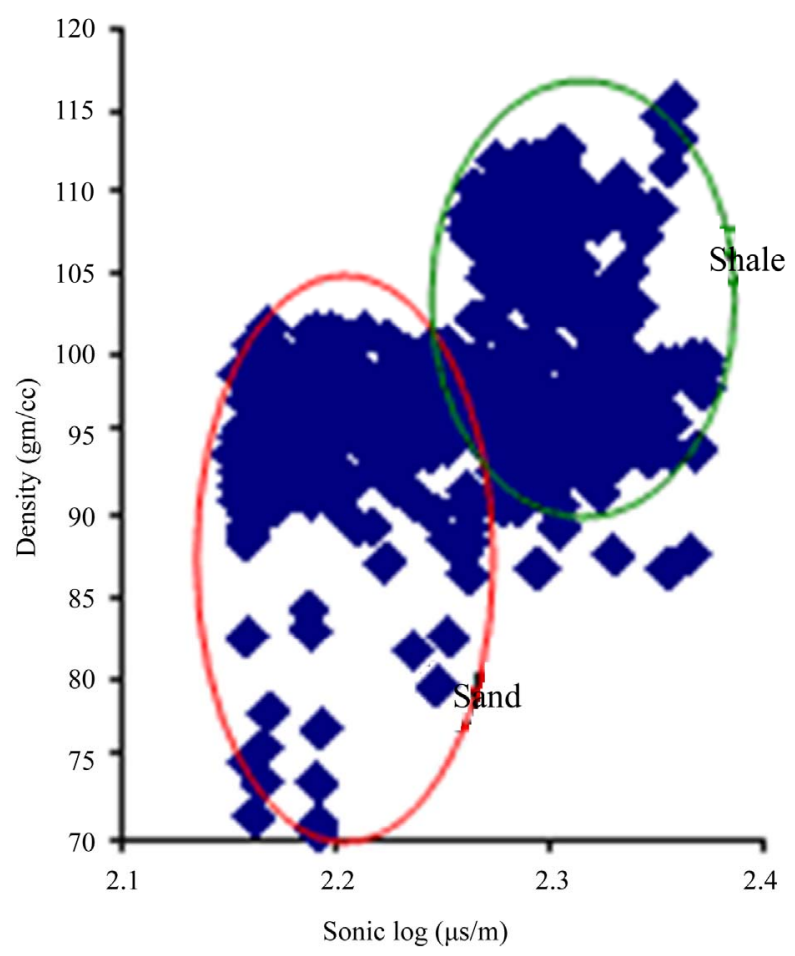

Figure 5. Crossplot of density and sonic transittime at wells A.

coded with shale volume juxtaposed on depth trend models shows a parabolic relationship determining the pore fluid types (Figure 7). Finally, in order to understand the finer details of the hydrocarbon-bearing zones, rock physics crossplots of well-log data coloured in terms hydrocarbon saturation juxtaposed on depth trend models for shale (blue), brine sands (red), oil sands (red), and gas sands (yellow) were generated and as shown in Figure 8.

These plots (Figures 7 and 8) indicate that sand, and shale facies are clearly separable in the smaller interval (1.0 - 2.0 unit) and that effective porosity plays a crucial role in hydrocarbon accumulation in this area. juxtaposed on depth trend models for shale (blue), brine sands (red), oil sands (red), and gas sands (yellow).

\section{Conclusions}

This study showed that velocity-porosity and impedanceporosity relation for Agbada Formation in Eve Field is nonlinear. Three main trends are recognized: one for clean sands of the stratigraphic units, one for dirty sands and other for shales units. The plots between $\mathrm{Vp} / \mathrm{Vs}$ and acoustic impedance colour coded with shale volume juxtaposed on depth trend models shows a parabolic relationship. These plots indicate that sand, and shale facies are clearly separable within a small reservoir interval.

A change in compaction trend from depth-velocity 

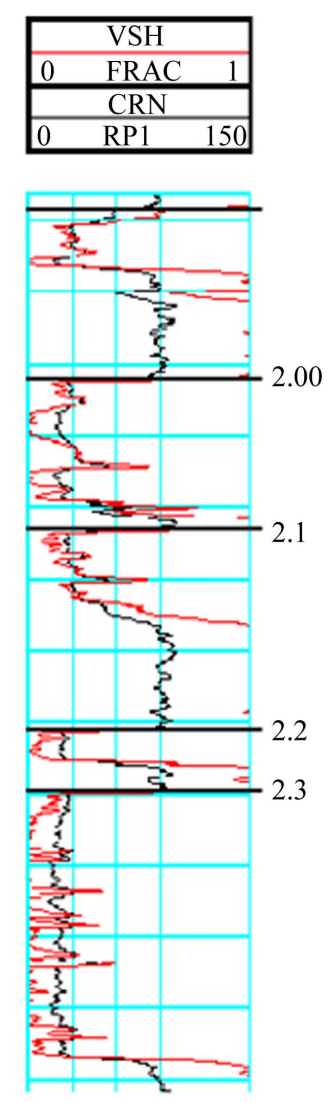

TVDSS

$\mathrm{m}$

\begin{tabular}{|c|c|c|}
\hline & CNL NORM & POR COR \\
\hline & $.47 \quad$ PU -.13 & FRAC .5 \\
\hline RTN & FDC NORM & POPDO 1 \\
\hline .2 OHMM 2000 & $1.8 \mathrm{G} / \mathrm{CC} \quad 2.8$ & $\begin{array}{ll}\text { FRRC } & .5 \\
\end{array}$ \\
\hline
\end{tabular}

2165

2180

2195

2210

2225

2240

2255

2270

2285

2300

2315

2330
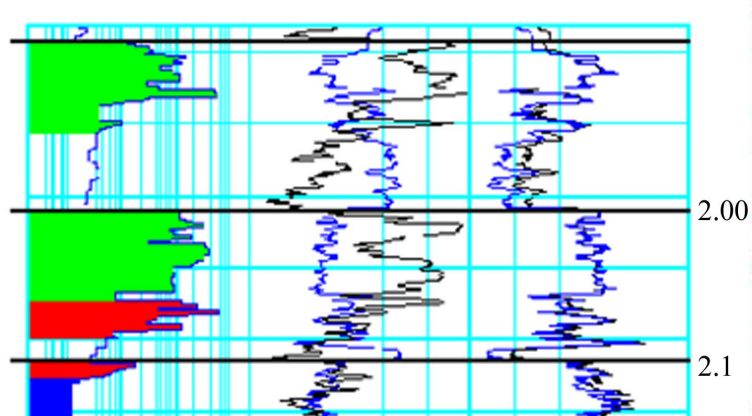

.1
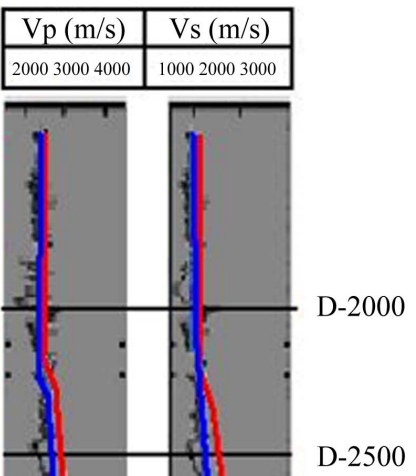

Figure 6. Rock physics depth trends for shales (blue) and sands (red), juxtaposed on well-log data from Well B penetrating D levels.

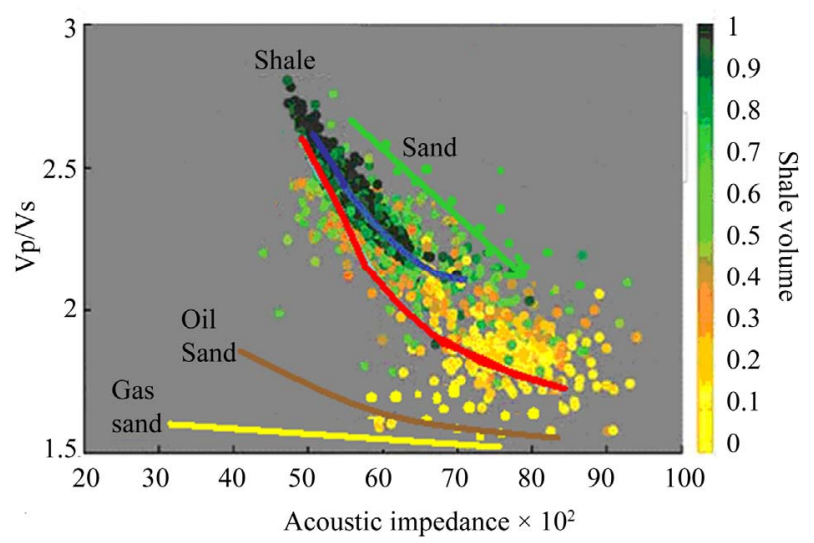

Figure 7. Rock physics crossplots of well-log data colored in terms of shale volume, juxtaposed on depth trend models for shale (blue), brine sands (red), oil sands (brown), and gas sands (yellow).

crossplot is related to changes in porosity in Eve Field. Compaction trends are nonlinear and have proved to be a powerful tool to predict porosity and gamma ray curves, from interval transit time measured from sonic log.

This study also showed that a systematic approach com-bined with determination of compaction trend tech-

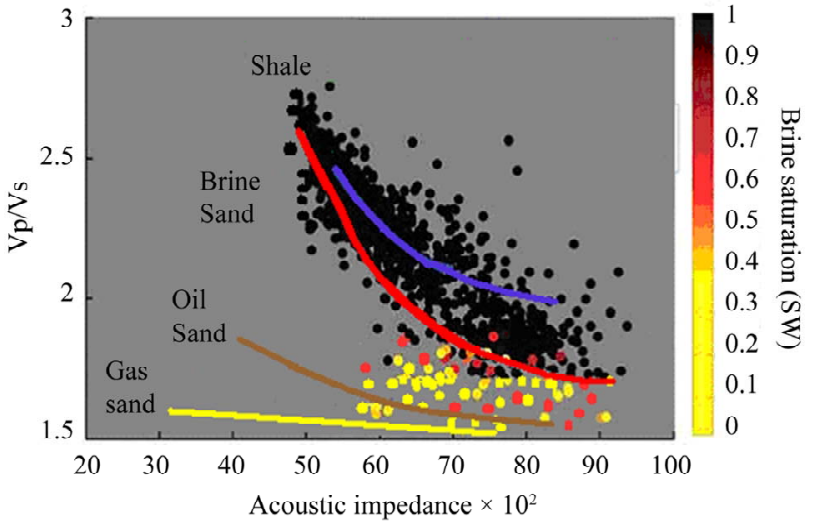

Figure 8. Rock physics crossplots of well-log data coloured in terms hydrocarbon saturation.

niques helped in understanding the subsurface, and allowed precise mapping of lithology. Predicting effective porosity through determination of compaction trends has provided a very high degree of confidence in analyzing the porous and nonporous zones of the reservoir. This study has been very helpful in providing more meaningful geologic information about the extent, shape and lateral lithological variation of reservoirs. 


\section{Acknowledgements}

We would like to acknowledge Department of Petroleum Resources (DPR) for supplying the data used for the study. We sincerely appreciate our colleagues for constructive reviews and two other anonymous referees.

\section{References}

[1] L. F. Athy, "Density, Porosity and Compaction of Sedimentary Rocks,” AAPG Bulletin, Vol. 14, No. 1, 1930, pp. 1-24.

[2] B. Baldwin and C. O. Butler, "Compaction Curves," AAPG bulletin, Vol. 69, No. 4, 1985, pp. 622-626.

[3] K. Bjørlykke, "Clay Mineral Diagenesis in Sedimentary Basins-A Key to the Prediction of Rock Properties; Examples from the North Sea Basin,” Clay Minerals, Vol. 33, No. 1, 1998, pp. 15-34.

[4] S. N. Ehrenberg, "Relationship between Diagenesis and Reservoir Quality in Sandstones of the Garn Formation, Haltenbanken, Mid-Norwegian Continental Shelf,” AAPG Bulletin, Vol. 74, No. 10, 1990, pp. 1538-1558.

[5] Z. Haung and F. Gradstein, "Depth-Porosity Relationship from Deep Sea Sediments,” Scientific Drilling, Vol. 1, 1990, pp. 157-162.

[6] R. R. Hills, "Quantifying Erosion in Sedimentary Basins from Sonic Velocity in Shales and Sandstone,” Exploration Geophysics, Vol. 24, 1993, pp. 561-566. doi:10.1071/EG993561

[7] C. E. Hottman and R. K. Johnson, "Estimation of Formation Pressures from Log-derived Shale Properties,” Journal of Petroleum Technology, Vol. 17, No. 6, 1965, pp. 717-722. doi:10.2118/1110-PA

[8] H. H. Haldorsen, and L. W. Lake, "A New Approach to Shale Management in Field-Scale Simulation Models," The Journal of Petroleum Technology, Vol. 24, No. 4, 1984, pp. 447-457.

[9] D. R. Issler, “A New Approach to Shale Compaction and Stratigraphic Restoration, Beaufrt-MackenZie Basin and Mackenzie Corridor, Northern Canada,” AAPG Bulletin, Vol. 76, No. 8, 1992, pp. 1170-1189.

[10] P. Japsen, "Influence of Lithology and Neogene Uplift on Seismic Velocities in Denmark: Implications for Depth Conversions of Maps,” AAPG Bulletin, Vol. 77, No. 2, 1993, pp. 194-211.
[11] G. Korvin, "Shale Compaction and Statistical Physics," Geophysical Journal of the Royal Astronomical Society, Vol. 78, No. 1, 1984, pp. 35-50. doi:10.1111/j.1365-246X.1984.tb06470.x

[12] D. K. Larue and H. Legarre, "Flow Units, Connectivity, and Reservoir Characterization in a Wave-Dominated Deltaic Reservoir: Meren Reservoir, Nigeria”, AAPG Bulletin, Vol. 88, 2004, pp. 303-324. doi:10.1306/10100303043

[13] G. Liu and E. Roaldset, “A New Decompaction Model and it Applications to the Northern North Sea," First Break, Vol. 12, 1994, pp. 81-89.

[14] K. Magara, “Thickness of Removed Sedimentary Rocks, Paleopore Pressure, and Paleotemperature, Southwestern Part of Western Canada basin,” AAPG Bulletin, Vol. 60, 1976, pp. 554-566.

[15] K. Magara, "Comparison of Porosity-Depth Relationships of Shale and Sandstone,” Journal of Petroleum Geology, Vol. 3, No. 2, 1980, pp. 92-102. doi:10.1111/j.1747-5457.1980.tb00981.x

[16] Schlumberger, "Log Interpretation Principle and Applications,” Schlumberger education Services, Houston, 1989, p. 46.

[17] J. W. Schmoker and R. B. Halley, "Carbonate Porosity versus Depth: A Predictable Relation for South Florida," AAPG Bulletin, Vol. 66, No. 12, 1982, pp. 2561-2570.

[18] J. G. Sclater and P. A. F. Christie, "Continental Stretching: An Explanation of Post Mid-Cretaceous Subsidence of the Central North Sea," Journal of Geophysical Research, Vol. 85, No. B7, 1980, pp. 3711-3739. doi:10.1029/JB085iB07p03711

[19] R. C. Selley, "Porosity gradient in the North Sea oil-bearing sandstones," Journal of the Geological Society of London, Vol. 135, No. 1, 1978, pp. 119-132. doi:10.1144/gsjgs.135.1.0119

[20] B. F. M. Stam, G. P. Lloyd and D. Gillis, "Algorithm for Porosity and Subsidence History,” Computers and Geosciences, Vol. 13, No. 4, 1987, pp. 317-349. doi:10.1016/0098-3004(87)90006-9

[21] J. M. Weller, “Compaction of Sediments,” AAPG Bulletin, Vol. 43, No. 2, 1959, pp. 273-310.

[22] M. R. Wyllie, J. A. R. Gregory and G. H. F. Gardner, "An Experimental Investigation of Factors Affecting Elastic Waves Velocities in Porous Media,” Geophysics, Vol. 23, 1958, pp. 459-493. doi:10.1190/1.1438493 